\title{
Is metformin use associated with changes in urinary parameters in stone formers?
}

Daniel C. Rosen, Jacob N. Bamberger; Elie Kaplan-Marans; Ishan Paranjpe; Arjun Kapoor; Blair Gallante; Daniel J. Atashsokhan; Anna M. Zampini; Johnathan A. Khusid; William M. Atallah; Mantu Gupta

Department of Urology, Icahn School of Medicine at Mount Sinai, New York, NY, United States

Cite as: Rosen DC, Bamberger JN, Kaplan-Marans E, et al. Is metformin use associated with changes in urinary parameters in stone formers? Can Urol Assoc J 2021 September 24; Epub ahead of print. http://dx.doi.org/10.5489/cuaj.7344

Published online September 24, 2021

Corresponding author: Dr. Daniel C. Rosen, Department of Urology, Icahn School of Medicine at Mount Sinai, New York, NY, United States; Drosen@chesuro.com

$* * *$

\section{Abstract}

Introduction: Diabetes mellitus (DM) is associated with an increased risk of nephrolithiasis and is often treated with metformin. The relationship between metformin and nephrolithiasis formation remains unclear as studies have demonstrated conflicting results.

Methods: We conducted a cross-sectional analysis of stone-forming patients at our stone clinic prior to the initiation of stone-directed medical management. Patients were grouped based on diabetic status and diabetic medication regimen. Outcomes evaluated were 24-hour urinary parameters and specimen stone type using univariate Kruskal-Wallis and Chi-squared analyses. Multivariate analyses controlling for metabolic syndrome components and $\mathrm{HbAlc}$ were performed.

Results: Data were available for 505 patients, of whom 147 were diabetic and 358 were not. On multivariate analyses controlling for $\mathrm{HbAlc}$ and other comorbidities, diabetic patients on metformin still had worse urinary parameters, including urine $\mathrm{pH}$, than non-diabetic patients $(\mathrm{pH}$ $=-0.33,-0.37, \mathrm{p}<0.05)$. Patients with $\mathrm{DM}$ on metformin did not exhibit significant differences in 24-hour urine findings compared to patients with DM not on metformin ( $p>0.05$ for all urinary parameters).

Conclusions: Stone-forming patients with DM on metformin were associated with urinary abnormalities similar to those not on metformin. Cohort studies comparing urinary parameters of 
patients prospectively started on metformin are necessary to further elucidate metformin's role, if any, in combatting nephrolithiasis.

\section{Introduction}

In the United States, the lifetime prevalence of nephrolithiasis approaches $10 \%$ while annual healthcare expenditures managing the disease exceed $\$ 2.1$ billion. ${ }^{1,2}$ Kidney stones in the general population have a recurrence rate of $>30 \%{ }^{3}$ and understanding the etiology of the disease as well as modifiable factors driving stone formation is of paramount importance. Metabolic and epidemiological studies have identified an association between type 2 diabetes mellitus (DM) and nephrolithiasis. ${ }^{4,5}$ Insulin resistance, which is the hallmark of DM, is known to induce intracellular acidosis and impair ammoniagenesis in the proximal tubule, both of which contribute to a heightened risk for stone formation, particularly for uric acid stones. ${ }^{5,6} \mathrm{In}$ fact, in a cross-sectional study, the prevalence of nephrolithiasis in patients with DM was reported to be $21 \%$ compared to $9 \%$ in patients without DM. ${ }^{7}$ These metabolic changes suggest there may be medical targets in the glycemic and insulin pathways that may decrease stone recurrence rate.

Currently, a common option for first-line medical management for type II DM is metformin. ${ }^{8}$ Metformin functions through several mechanisms, including decreasing hepatic gluconeogenesis and increasing gut utilization of glucose. ${ }^{9,10}$ Although many studies have investigated the interplay of metabolic derangements and shared risk factors such as age, body mass index (BMI), and diet, as they relate to DM and nephrolithiasis, ${ }^{9}$ studies investigating how diabetic medications affect the likelihood of developing kidney stones are sparse. Theoretically, a diabetic medication could improve urinary parameters and reduce stone recurrence if the driving force behind the stone formation is related to diabetes. If in fact DM medication selection is associated with stone risk, this may inform DM treatment strategies in diabetic stone formers. Accordingly, in this study, we aim to determine if there are any differences in stone-forming patients based on their diabetic medications, most prominently metformin.

\section{Methods}

\section{Data source and patient population}

After obtaining Institutional Review Board approval, we retrospectively examined our database of kidney stone-forming patients who underwent initial metabolic workup at our comprehensive, tertiary stone clinic in New York City, New York between June, 2016 and October, 2020.

Patients with both a metabolic workup prior to initiation of medical management and a history of kidney stones were included in the study. 


\section{Patient demographics, clinical, and urinary parameters}

Demographics, BMI, HbA1c, prescription medications, and medical history were obtained from patients' electronic medical record. Patients were categorized based on Metabolic Syndrome Severity Score (MSSS) ${ }^{11}$ and American Diabetes Association status. ${ }^{12}$ Urinary parameters were collected using Litholink 24-hour urine analyses (Litholink, Chicago, IL, USA). Litholink standardized normal ranges were used as the lower and upper limits of normal.

\section{Diabetic status and metformin usage}

Patients were categorized into one of the following categories: non-diabetic (No-DM), diabetic but not taking metformin (DM-NoMet), diabetic on metformin monotherapy (DM-Met), or diabetic on metformin and another oral diabetic medication (DM-Met-Other). Other oral diabetic mediations included dipeptidyl peptidase-4 (DPP-4) inhibitors (i.e., sitagliptin), sulfonylureas (i.e., glipizide, glimepiride), and SGLT2 inhibitors (i.e., canagliflozin). As there were too few patients on each of these additional medications for meaningful statistical analysis, they were grouped together in order to see if there were any potential additive effects of multiple medications in addition to metformin.

Usage of metformin and/or other hypoglycemics such as insulin could affect urinary parameters but could also reflect worsening diabetic status, which independent of medication usage can affect urinary parameters. To address the two potential confounding effects of diabetic severity and insulin usage, a within-group comparison of urinary parameters between insulin and non-insulin users was performed in the DM-Met-Other and DM-NoMet groups. In addition, a multivariate analysis controlling for BMI and $\mathrm{HbA1c}$ (indicators of diabetic severity) was performed.

\section{Stone analysis}

Stone samples, either spontaneously passed or surgically retrieved, were analyzed using infrared spectroscopy (LITSA Litholink Stone Analysis, Itasca IL). Stones were categorized into one of three groups: $>50 \%$ calcium oxalate $(\mathrm{CaOx}),>50 \%$ uric acid (UA), or other/mixed based on reported compositions.

\section{Statistical analysis}

Baseline patient characteristics were compared between the four groups using Kruskal-Wallis test for continuous variables and chi-square for categorical variables. Univariate comparison of urinary parameters between study cohorts was performed using Kruskal-Wallis tests. Multivariate linear regressions were performed to analyze the association between 24-hour urinary parameters and DM management, adjusting for patient characteristics including age, BMI, HbAlc, hypertension, hyperlipidemia, and hypertriglyceridemia. Two different multiple linear regressions of 24-hour urinary parameters were performed - one using the No-DM group 
as a reference and another using the DM-NoMet group as a reference. Binomial regression was used to analyze the relationship between DM management groups and stone composition. All analyses were two-tailed and performed using Stata/MP software version 14.1 (StataCorp, College Station, TX).

\section{Results}

\section{Patient characteristics and demographics}

In total, 505 patients were included in the study. Table 1 presents baseline characteristics of the patients: 358 (71\%) were No-DM, 44 (9\%) were DM-NoMet, 54 (11\%) were DM-Met, and 49 $(10 \%)$ were DM-Met-Other. Median age significantly differed across the four groups with NoDM having the lowest median age (61.5 for DM-NoMet, 60 for DM-Met, DM-Met-Other groups, and 57 for the NoDM group, years, $p=0.007)$. The DM-Met group had the highest BMI (29.8 vs. 26.5, $p<.001$ ), and the DM-Met and DM-Met-Other groups had the highest HbA1c levels compared to No-DM $(6.7 \%$ vs. $5.5 \%, p<.001)$.

The DM-Met group had the highest rates of hypertension ( $70 \%$ vs. $61 \%, p<.001)$ and hyperlipidemia ( $53 \%$ vs. $48 \%, p<.001$ ), while the DM-Met-Other group had highest rates of hypertriglyceridemia ( $65 \%$ vs. $64, p<.001 \%$ ).

\section{Insulin usage}

In a sub-analysis, 9 patients (20\%) in the DM-NoMet and 13 patients (26\%) in the DM-MetOther group were reported as currently taking insulin. No significant difference was found in a comparison of urinary parameters between insulin and non-insulin users within either group.

\section{Severity of urine parameter derangements and effects of metformin}

Univariate comparison of patient urine parameters, stratified by study cohort, are presented in Table 2. All three diabetic groups had statistically significantly lower urine $\mathrm{pH}$ ( $<5.7$ vs. 6.0, $p<.001)$ and higher SSUA compared to patients without DM ( $>0.9$ vs. $0.7, p<.001)$. Patients in the DM-Met group had a statistically higher urine citrate excretion $(879 \mathrm{mg} / \mathrm{d}$ vs. $555 \mathrm{mg} / \mathrm{d}$, $p<.0 .001)$ compared to all other groups. There was no statistical difference in urinary uric acid noted between groups $(p=0.3)$. Patients without diabetes had a lower median 24-hour urine volume $(1.7 \mathrm{~L}, p=0.045)$ and higher $\operatorname{SSCaP}(0.8, p<0.001)$ compared to patients with DM. Two multivariate analyses of 24-hour urine parameters were conducted adjusting for age, BMI, hypertension, hyperlipidemia, hypertriglyceridemia and $\mathrm{HbAlc}$. In the first analysis using the NoDM group as a referent (Table 3), DM-Met and DM-Met-Other had the biggest differences in urinary $\mathrm{pH}(\beta=-0.33$ and $-0.37, p<0.05)$. In the second analysis with the DM-NoMet group held as a referent (Table 4), the DM-MET-Other group had significantly greater levels of citrate than patients not on metformin $(+396.85 p=0.001)$ while the differences in $\mathrm{pH}$ and SSUA were not seen. 


\section{Stone analysis}

In total 229 patients (45.3\%) had stone analysis data available (Table 5). Among them, NoDM had the highest rate of predominately $\mathrm{CaOx}$ stones which was significantly greater than in the DM-Met group ( $75 \%$ vs. $61.5 \%, p<0.05$ ). Conversely, $30.8 \%$ of patients in the DM-Met group and $23.5 \%$ of patients in the DM-Met-Other group formed predominately uric acid stones which was significantly greater than the $10.3 \%$ of patients in the NoDM group $(p=0.0001$ and $p=0.032$, respectively). However, a second logistic regression was conducted using the DM-NoMet group as a referent and revealed no significant associations between our patient groups and observed stone compositions $(p>0.05)$.

\section{Discussion}

Metformin is a commonly utilized first-line treatment for patients with type II DM, ${ }^{13}$ which are a population at an increased risk for nephrolithiasis. ${ }^{14}$ Metformin helps lower blood glucose levels by increasing insulin sensitivity in peripheral tissues, decreasing hepatic gluconeogenesis, and decreasing glucose absorption in the small intestine. ${ }^{10}$ Additionally, metformin has been suggested to have a protective role in calcium oxalate nephrolithiasis formation on a molecular level. Studies in mice have recently shown metformin to limit renal crystal deposition through decreased inflammation, ${ }^{15}$ and it has been shown to behave as an antioxidant. ${ }^{16}$ In particular, monocyte chemoattractant protein 1 (MCP-1) and osteopontin (OPN) are inflammatory mediators that have been implicated in calcium oxalate stone genesis ${ }^{17}$ but are downregulated by metformin. ${ }^{15}$ Metformin has recently been reported to acidify the urine, which would actually encourage uric acid stone formation. ${ }^{18}$ Yet, despite metformin's common use among patients with DM and the increased proclivity of patients with DM to form kidney stones, ${ }^{14,19,20}$ there have been no large scale studies to date examining its relationship to the 24-hour urinary parameters associated with stone risk. To this end, we present a cross-sectional analysis of urine parameters in stone formers stratified by metformin usage.

On multivariate analysis, we did not identify a significant association between metformin use and the urinary parameters associated with stone risk, in particular urinary $\mathrm{pH}$, the driving factor behind uric acid stone formation. As expected, this relationship did appear prominently on univariate analysis (Table 2) and in an increased number of uric acid stones (Table 5). There are several reasons why we may not be observing the reported effects in clinical practice. Though prior animal studies ${ }^{15}$ have suggested a protective effect of metformin use in stone formers, these studies evaluated calcium oxalate stones and the added stone risk among patients with DM that we would expect metformin to target stems primarily from uric acid containing stones.

Metformin's theoretical glycemic protective effects from uric acid stone formation were not seen in the urinary parameters; urinary $\mathrm{pH}$ did not vary between DM-NoMet, DM-Met, and DM-MetOther groups. Furthermore, SSUA was not significantly different between DM-Met compared to DM-NoMet groups. The clear signal that was seen was that all diabetic groups had a 
significantly lower urine $\mathrm{pH}$ compared to non-diabetic stone-formers. Taken together, metformin use (when controlling for $\mathrm{HbAlc}$ and diabetic status) was not associated with improved urinary parameters in these stone forming patients.

Interestingly we observed that the DM-Met-Other group had significantly higher urine citrate levels compared to all other groups. We postulate that this could be related to increased citrate production by some of the newer diabetic medications, such as sitagliptin. However, the number of patients in this category, combined with the great variety of different regimens used, precluded sub-analysis of different medication regimens. Accordingly, the relationship between non-metformin oral hypoglycemics and urinary parameters represents an avenue for further research, as prior studies have suggested possible protective effects of these medications. ${ }^{21}$

This study is a hypothesis-generating study due to its retrospective and cross-sectional nature and accordingly we were unable to determine changes in urinary parameters prior to and after initiation of the medications examined. Furthermore, all patients originated from a single tertiary stone center and accordingly may not represent the stone-forming population at large. There were insufficient numbers of patients on oral hypoglycemic medications other than metformin to study the impacts of these additional medications. Despite these limitations, we believe our study provides an important contribution to the literature regarding medication selection for diabetic stone formers and has several surprising findings, in particular the increase in citrate in patients on multiple medications as well as the apparent lack of protective effects of metformin in stone-forming patients. We recommend further research in a prospective longitudinal fashion to validate our findings and determine the impact of other diabetic medication on 24-hour urine parameters and stone risk, an area ripe for therapeutic targeting despite the present study's negative result. In addition, a further avenue of research may explore the role ethnicity, diet, and socioeconomic status as these factors may have an impact on changes in urinary parameters in response to DM medications.

\section{Conclusions}

Metformin use by diabetic stone formers does not appear to be associated with independent changes to these urinary parameters, though use of metformin in combination with other diabetic medications was associated with higher citrate levels. Further research via a prospective, multiinstitutional study is recommended to validate our findings regarding metformin and to further explore the potential for citraturia associated with other diabetic medications. 


\section{References}

1. Ziemba JB and Matlaga BR: Epidemiology and economics of nephrolithiasis. Investig. Clin. Urol. 2017; 58: 299-306.

2. Lotan Y: Economics and Cost of Care of Stone Disease. Adv. Chronic Kidney Dis. 2009; 16: 5-10.

3. Rule AD, Lieske JC, Li X, et al: The ROKS nomogram for predicting a second symptomatic stone episode. J. Am. Soc. Nephrol. 2014; 25: 2878-2886. Available at: www.jasn.org, accessed January 13, 2021.

4. West B, Luke A, Durazo-Arvizu RA, et al: Metabolic Syndrome and Self-Reported History of Kidney Stones: The National Health and Nutrition Examination Survey (NHANES III) 1988-1994. Am. J. Kidney Dis. 2008; 51: 741-747. Available at: https://linkinghub.elsevier.com/retrieve/pii/S0272638608000620, accessed August 11, 2019.

5. Taylor EN, Stampfer MJ and Curhan GC: Diabetes mellitus and the risk of nephrolithiasis. Kidney Int. 2005; 68: 1230-1235.

6. Ann Cameron M, Maalouf NM, Adams-Huet B, et al: Urine Composition in Type 2 Diabetes: Predisposition to Uric Acid Nephrolithiasis. J Am Soc Nephrol 2006; 17: 1422-1428. Available at: www.jasn.org., accessed August 9, 2019.

7. Meydan N, Barutca S, Caliskan S, et al: Urinary stone disease in diabetes mellitus. Scand. J. Urol. Nephrol. 2003; 37: 64-70.

8. Sanchez-Rangel $\mathrm{E}$ and Inzucchi SE: Metformin: clinical use in type 2 diabetes. Diabetologia 2017; 60: 1586-1593.

9. Nerli R, Jali M, Guntaka AK, et al: Type 2 diabetes mellitus and renal stones. Adv. Biomed. Res. 2015; 4: 180.

10. Rena G, Hardie DG and Pearson ER: The mechanisms of action of metformin. Diabetologia 2017; 60: 1577-1585. Available at: /pmc/articles/PMC5552828/?report=abstract, accessed January 13, 2021.

11. Alberti KGMM, Zimmet P and Shaw J: Metabolic syndrome - A new world-wide definition. A consensus statement from the International Diabetes Federation. Diabet. Med. 2006; 23: 469-480.

12. Anon: Diagnosing Diabetes and Learning About Prediabetes: American Diabetes Association ${ }^{\circledR}$. Available at: http://www.diabetes.org/diabetes-basics/diagnosis/, accessed June 30, 2019.

13. Association AD: 9. Pharmacologic Approaches to Glycemic Treatment: Standards of Medical Care in Diabetes - 2019. Diabetes Care 2019; 42: S90-S102. Available at: https://care.diabetesjournals.org/content/42/Supplement_1/S90, accessed August 9, 2019.

14. Shoag J, Tasian GE, Goldfarb DS, et al: The New Epidemiology of Nephrolithiasis. Adv. Chronic Kidney Dis. 2015; 22: 273-278.

15. Yang X, Yang T, Li J, et al: Metformin prevents nephrolithiasis formation by inhibiting the expression of OPN and MCP-1 invitro and invivo. Int. J. Mol. Med. 2019; 43: 16111622. Available at: http://www.ncbi.nlm.nih.gov/pubmed/30720053, accessed July 21, 
2019.

16. Yang X, Ding H, Qin Z, et al: Metformin Prevents Renal Stone Formation through an Antioxidant Mechanism In Vitro and In Vivo. Oxid. Med. Cell. Longev. 2016; 2016: 110. Available at: http://www.ncbi.nlm.nih.gov/pubmed/27781075, accessed July 21, 2019.

17. Khan SR: Is oxidative stress, a link between nephrolithiasis and obesity, hypertension, diabetes, chronic kidney disease, metabolic syndrome?

18. Yarovoi SK, Kareva EN and Dzhalilov O V: [Effects of oral hypoglycemic drugs on lithogenic properties of urine in nephrolithiasis patients with concurrent type 2 diabetes]. Urologiia 2018: 63-69. Available at: http://www.ncbi.nlm.nih.gov/pubmed/30035421, accessed August 9, 2019.

19. Scales CD, Smith AC, Hanley JM, et al: Prevalence of kidney stones in the United States. Eur. Urol. 2012; 62: 160-5. Available at: http://www.ncbi.nlm.nih.gov/pubmed/22498635, accessed March 30, 2019.

20. Domingos F and Serra A: Nephrolithiasis is associated with an increased prevalence of cardiovascular disease. Nephrol. Dial. Transplant. 2011; 26: 864-868. Available at: https://pubmed.ncbi.nlm.nih.gov/20709737/, accessed April 9, 2021.

21. Kristensen KB, Henriksen DP, Hallas J, et al: Sodium-glucose cotransporter 2 inhibitors and risk of nephrolithiasis. Diabetologia 2021: 1-9. Available at: https://doi.org/10.1007/s00125-021-05424-4, accessed April 9, 2021.

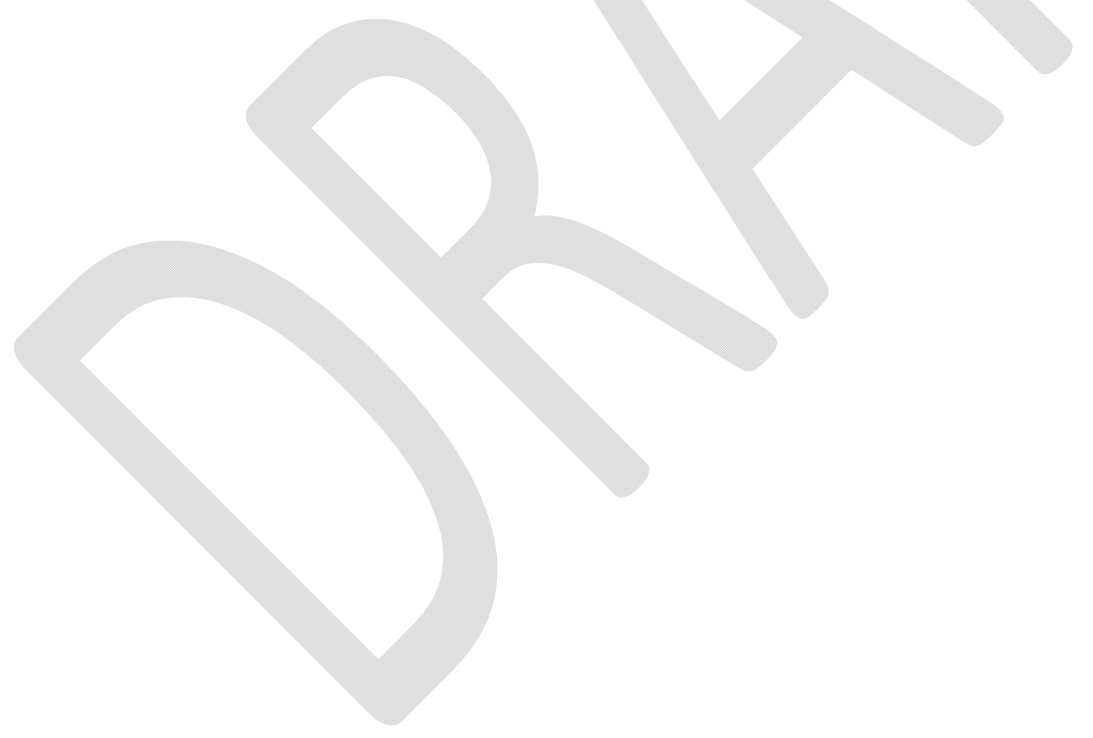


$C U A J$ - Original Research

Rosen et al

Relationship between metformin and nephrolithiasis

Figures and Tables

Table 1. Baseline patient characteristics stratified by study cohort

\begin{tabular}{|c|c|c|c|c|c|}
\hline & \multirow[b]{2}{*}{$\begin{array}{c}\begin{array}{c}\text { Non-diabetic } \\
\text { (No-DM) } \\
\mathrm{n}=358(70.9 \%)\end{array}\end{array}$} & \multicolumn{3}{|c|}{ Diabetic } & \multirow[b]{2}{*}{$\mathbf{p}$} \\
\hline & & $\begin{array}{c}\text { No } \\
\text { metformin } \\
\text { (DM-NoMet) } \\
\mathrm{n}=44(8.7 \%)\end{array}$ & $\begin{array}{c}\begin{array}{c}\text { Metformin } \\
\text { only } \\
\text { (DM-Met) } \\
\mathrm{n}=54(10.7 \%)\end{array}\end{array}$ & $\begin{array}{c}\text { Metformin \& } \\
\text { other } \\
\text { (DM-Met- } \\
\text { Other) } \\
\text { n=49 }(9.7 \%) \\
\end{array}$ & \\
\hline \multicolumn{6}{|l|}{ Median (IQR): ${ }^{a}$} \\
\hline Age, years & $\begin{array}{c}57.0(43.0, \\
66.0)\end{array}$ & $\begin{array}{c}61.5(55.5, \\
69.5)\end{array}$ & $\begin{array}{c}60.0(50.0, \\
68.0)\end{array}$ & $\begin{array}{c}60.0(53.0 \\
66.0)\end{array}$ & 0.007 \\
\hline BMI, $\mathrm{kg} / \mathrm{m}^{2}$ & $\begin{array}{c}26.5(23.3, \\
29.6)\end{array}$ & $\begin{array}{c}28.5(26.3, \\
34.9)\end{array}$ & $\begin{array}{c}29.8(27.4 \\
34.4)\end{array}$ & $\begin{array}{c}29.0(26.7, \\
32.5)\end{array}$ & $<0.001$ \\
\hline $\mathrm{HbA1c,} \%$ & $5.5(5.2,5.8)$ & $6.6(6.3,7.3)$ & $6.7(6.3,7.4)$ & $6.7(6.4,7.8)$ & $<0.001$ \\
\hline $\begin{array}{l}\text { Serum uric acid, } \\
\mathrm{mg} / \mathrm{dL}\end{array}$ & $5.4(4.4,6.8)$ & $6.0(4.4,7.2)$ & $5.8(4.5,6.8)$ & $5.8(5.3,6.3)$ & 0.9 \\
\hline $\mathrm{n}(\%) \mathrm{e}^{\mathrm{b}}$ & 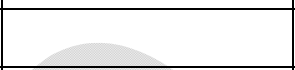 & & +2 & & \\
\hline Sex & 2 & 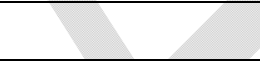 & +2 & & \\
\hline Male & $194(54.8)$ & $23(52.3)$ & $33(61.1)$ & $32(65.3)$ & 0.4 \\
\hline Female & $160(45.2)$ & $21(47.7)$ & $21(38.9)$ & $17(34.7)$ & \\
\hline Hypertension & 97 (27.6) & 27 (61.4) & $38(70.4)$ & $29(59.2)$ & $<0.001$ \\
\hline Hyperlipidemia & $74(21.1)$ & $21(47.7)$ & $28(52.8)$ & $21(42.9)$ & $<0.001$ \\
\hline Hypertriglyceridemia & $78(22.2)$ & $24(55.8)$ & $34(63.0)$ & $31(64.6)$ & $<0.001$ \\
\hline \multicolumn{6}{|l|}{ MSSS } \\
\hline+2 & $175(50.1)$ & $0(0.0)$ & $1(1.9)$ & $0(0.0)$ & $<0.001$ \\
\hline$y^{2}$ & $81(23.2)$ & $10(23.3)$ & $2(3.8)$ & $4(8.3)$ & \\
\hline 2 & $42(12.0)$ & $8(18.6)$ & $7(13.2)$ & $13(27.1)$ & \\
\hline 3 & $40(11.5)$ & $3(7.0)$ & $22(41.5)$ & $12(25.0)$ & \\
\hline 4 & $11(3.2)$ & $15(34.9)$ & $14(26.4)$ & $14(29.2)$ & \\
\hline 5 & $0(0.0)$ & $7(16.3)$ & $7(13.2)$ & $5(10.4)$ & \\
\hline
\end{tabular}

${ }^{a}$ Kruskal-Wallis test. ${ }^{b} \mathrm{Chi}$-square test. Significant values $(\mathrm{p}<0.05)$ bolded. BMI: body mass index; IQR: interquartile range; MSSS: Metabolic Syndrome Severity Score. 
CUAJ - Original Research

Rosen et al

Relationship between metformin and nephrolithiasis

\begin{tabular}{|c|c|c|c|c|c|}
\hline & \multirow[b]{2}{*}{$\begin{array}{c}\text { Non-diabetic } \\
\text { (No-DM) } \\
\mathrm{n}=358(70.9 \%)\end{array}$} & \multicolumn{3}{|c|}{ Diabetic } & \multirow[b]{2}{*}{$\mathbf{p}^{\mathbf{a}}$} \\
\hline & & $\begin{array}{c}\text { No metformin } \\
\text { (DM-NoMet) } \\
\text { n=44 (8.7\%) }\end{array}$ & $\begin{array}{c}\text { Metformin only } \\
\text { (DM-Met) } \\
n=54(10.7 \%)\end{array}$ & $\begin{array}{c}\begin{array}{c}\text { Metformin \& } \\
\text { other }\end{array} \\
\text { (DM-Met-Other) } \\
\mathrm{n}=49(9.7 \%) \\
\end{array}$ & \\
\hline \multicolumn{6}{|l|}{ Median (IQR) } \\
\hline Volume $^{\mathrm{b}}$ & $1.7(1.2,2.5)$ & $2.0(1.4,2.5)$ & $2.0(1.5,2.6)$ & $2.0(1.5,2.6)$ & 0.045 \\
\hline SS CaOx & $6.1(3.8,9.0)$ & $4.5(2.9,7.0)$ & $5.5(4.1,7.9)$ & $6.5(4.1,9.0)$ & 0.023 \\
\hline Calcium $^{\mathrm{c}}$ & $\begin{array}{c}165.3(108.0, \\
236.9)\end{array}$ & $\begin{array}{c}130.5(49.5 \\
177.3)\end{array}$ & $\begin{array}{c}149.0(96.0 \\
251.1)\end{array}$ & $\begin{array}{c}171.0(112.0, \\
263.0)\end{array}$ & 0.07 \\
\hline Oxalate $^{c}$ & $36.0(28.8,44.8)$ & $36.6(27.0,53.0)$ & $42.0(32.0,51.0)$ & $40.9(32.8,52.0)$ & 0.011 \\
\hline Citrate $^{\mathrm{c}}$ & $\begin{array}{c}531.5(353.7 \\
745.2)\end{array}$ & $\begin{array}{c}484.8(290.6 \\
693.2)\end{array}$ & $\begin{array}{c}555.0(348.5 \\
954.0)\end{array}$ & $\begin{array}{c}878.6(562.2 \\
1138.6)\end{array}$ & $<0.001$ \\
\hline $\mathrm{SS} \mathrm{CaP}$ & $0.8(0.3,1.6)$ & $0.2(0.1,0.8)$ & $0.3(0.1,0.7)$ & $0.3(0.1,0.8)$ & $<0.001$ \\
\hline $\mathrm{pH}$ & $6.0(5.6,6.5)$ & $5.6(5.4,6.1)$ & $5.7(5.3,6.2)$ & $5.6(5.4,6.0)$ & $<0.001$ \\
\hline SS UA & $0.7(0.2,1.6)$ & $1.2(0.6,1.5)$ & $0.9(0.5,2.1)$ & $1.1(0.8,2.1)$ & $<0.001$ \\
\hline Uric acid d & $0.6(0.5,0.8)$ & $0.5(0.4,0.8)$ & $0.7(0.5,0.8)$ & $0.7(0.5,0.8)$ & 0.3 \\
\hline Sodium $^{\mathrm{e}}$ & $\begin{array}{c}144.4(108.0 \\
199.8) \\
\end{array}$ & $\begin{array}{c}142.4(104.7 \\
205.6)\end{array}$ & $\begin{array}{c}165.6(118.6 \\
203.0)\end{array}$ & $\begin{array}{c}175.1(121.4 \\
203.1)\end{array}$ & 0.08 \\
\hline Ammonium $^{\mathrm{e}}$ & $34.0(24.3,45.2)$ & $33.1(19.0,45.9)$ & $35.0(25.1,47.0)$ & $32.2(22.1,41.3)$ & 0.7 \\
\hline
\end{tabular}

${ }^{a}$ Kruskal-Wallis test; ${ }^{b} \mathrm{~L} /$ day; ${ }^{c} \mathrm{mg} /$ day; ${ }^{\mathrm{d}} \mathrm{g} / \mathrm{day} ;{ }^{\mathrm{e}} \mathrm{mmol} /$ day. Significant $(\mathrm{p}<0.05)$ values bolded. SS CaOx: supersaturation calcium oxalate; SS CaP: supersaturation calcium phosphate; SS UA: supersaturation uric acid. 
Relationship between metformin and nephrolithiasis

\begin{tabular}{|c|c|c|c|c|c|c|c|}
\hline & \multirow{3}{*}{$\begin{array}{c}\text { Non- } \\
\text { diabetic } \\
\text { (No-DM) } \\
\mathrm{n}=358 \\
(70.9 \%) \\
\end{array}$} & \multicolumn{6}{|c|}{ Diabetic } \\
\hline & & \multicolumn{2}{|c|}{$\begin{array}{c}\text { No metformin } \\
\text { (DM-NoMet) } \\
\text { n=44 (8.7\%) }\end{array}$} & \multicolumn{2}{|c|}{$\begin{array}{c}\text { Metformin only } \\
\text { (DM-Met) } \\
\text { n=54 (10.7\%) }\end{array}$} & \multicolumn{2}{|c|}{$\begin{array}{c}\text { Metformin \& other } \\
\text { (DM-Met-Other) } \\
\text { n=49 (9.7\%) }\end{array}$} \\
\hline & & Difference & $\mathbf{p}$ & Difference & $\mathbf{p}$ & Difference & p \\
\hline Volume $^{\mathrm{b}}$ & Ref. & -0.03 & 0.9 & -0.01 & 0.9 & 0.21 & 0.4 \\
\hline $\mathrm{SSCaOx}$ & Ref. & -9.64 & 0.010 & -6.74 & 0.053 & -8.87 & 0.019 \\
\hline Calcium $^{\mathrm{c}}$ & Ref. & -83.61 & 0.013 & -14.58 & 0.6 & -33.76 & 0.3 \\
\hline Oxalate $^{c}$ & Ref. & -2.47 & 0.7 & -1.60 & 0.8 & 1.49 & 0.8 \\
\hline Citrate $^{\mathrm{c}}$ & Ref. & -172.03 & 0.07 & 25.74 & 0.8 & 199.66 & 0.039 \\
\hline SSCaP & Ref. & -0.87 & 0.002 & -0.60 & 0.022 & -0.61 & 0.030 \\
\hline $\mathrm{pH}$ & Ref. & -0.26 & 0.2 & -0.33 & 0.047 & -0.37 & 0.043 \\
\hline SSUA & Ref. & 0.19 & 0.5 & 0.52 & 0.050 & 0.19 & 0.5 \\
\hline Uric Acid $^{\mathrm{d}}$ & Ref. & -0.21 & 0.003 & 0.00 & 0.9 & -0.10 & 0.12 \\
\hline Sodium $^{\mathrm{e}}$ & Ref. & -15.05 & 0.5 & -2.30 & 0.9 & 2.63 & 0.9 \\
\hline Ammonium $^{\mathrm{e}}$ & Ref. & 4.57 & 0.4 & 3.36 & 0.5 & -0.69 & 0.9 \\
\hline $\begin{array}{l}\text { Serum uric } \\
\text { Acid }^{f}\end{array}$ & Ref. & 1.42 & 0.031 & 0.29 & 0.6 & 0.9 & 0.2 \\
\hline
\end{tabular}

${ }^{\mathrm{a} C}$ Covariates included in multiple linear regression analyses: age, body mass index, hypertension, hyperlipidemia, hypertriglyceridemia, and HbA1c; ${ }^{b} \mathrm{~L} /$ day; ${ }^{\mathrm{c}} \mathrm{mg} / \mathrm{day} ;{ }^{\mathrm{d}} \mathrm{g} / \mathrm{day} ;{ }^{\mathrm{e}} \mathrm{mmol} / \mathrm{day} ;{ }^{\mathrm{f}} \mathrm{mg} / \mathrm{dL}$. Significant $(p<0.05)$ values bolded SS CaOx: supersaturation calcium oxalate; SS CaP: supersaturation calcium phosphate; SS UA: supersaturation uric acid. 
Relationship between metformin and nephrolithiasis

\begin{tabular}{|c|c|c|c|c|c|c|}
\hline & \multirow{3}{*}{$\begin{array}{c}\text { Non- } \\
\text { diabetic } \\
\text { (No-DM) } \\
n=358 \\
(70.9 \%) \\
\end{array}$} & \multicolumn{5}{|c|}{ Diabetic } \\
\hline & & \multirow[t]{2}{*}{$\begin{array}{c}\text { No metformin } \\
\text { (DM-NoMet) } \\
n=44(8.7 \%)\end{array}$} & \multicolumn{2}{|c|}{$\begin{array}{c}\text { Metformin only } \\
\text { (DM-Met) } \\
n=54(10.7 \%)\end{array}$} & \multicolumn{2}{|c|}{$\begin{array}{c}\text { Metformin \& other } \\
\text { (DM-Met-Other) } \\
\text { n=49 }(9.7 \%)\end{array}$} \\
\hline & & & Difference & $\mathbf{p}$ & Difference & $\mathbf{p}$ \\
\hline Volume $^{\mathrm{b}}$ & - & Ref. & -0.02 & 0.9 & 0.26 & 0.3 \\
\hline $\mathrm{SSCaOx}$ & - & Ref. & 1.50 & 0.09 & 1.23 & 0.2 \\
\hline Calcium $^{\mathrm{c}}$ & - & Ref. & 60.78 & 0.1 & 69.72 & 0.09 \\
\hline Oxalate $^{c}$ & - & Ref. & 1.98 & 0.7 & 3.43 & 0.6 \\
\hline Citrate $^{c}$ & - & Ref. & 179.96 & 0.09 & 396.85 & 0.001 \\
\hline SSCaP & - & Ref. & 0.29 & 0.2 & 0.35 & 0.2 \\
\hline $\mathrm{pH}$ & - & Ref. & -0.07 & 0.7 & -0.09 & 0.7 \\
\hline SSUA & - & Ref. & 0.33 & 0.3 & 0.01 & 0.9 \\
\hline Uric acid $^{\mathrm{d}}$ & - & Ref. & 0.21 & 0.021 & 0.13 & 0.2 \\
\hline Sodium $^{\mathrm{e}}$ & - & Ref. & 14.27 & 0.6 & 24.68 & 0.4 \\
\hline Ammonium $^{\mathrm{e}}$ & - & Ref. & -1.85 & 0.8 & -3.33 & 0.6 \\
\hline Serum uric acid & - & Ref. & -0.83 & 0.3 & -0.24 & 0.7 \\
\hline
\end{tabular}

${ }^{\mathrm{a} C o v a r i a t e s ~ i n c l u d e d ~ i n ~ m u l t i p l e ~ l i n e a r ~ r e g r e s s i o n ~ a n a l y s e s: ~ a g e, ~ b o d y ~ m a s s ~ i n d e x, ~ h y p e r t e n s i o n, ~}$

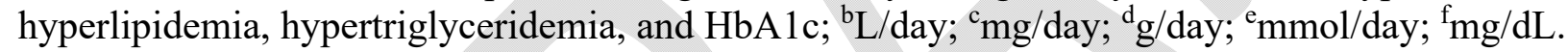

Significant $(\mathrm{p}<0.05)$ values bolded. SS CaOx: supersaturation calcium oxalate; SS CaP: supersaturation calcium phosphate; SS UA: supersaturation uric acid. 


\begin{tabular}{|c|c|c|c|c|c|c|c|c|c|}
\hline & \multicolumn{3}{|c|}{ Calcium oxalate } & \multicolumn{3}{|c|}{ Uric acid } & \multicolumn{3}{|c|}{ Mixed/other } \\
\hline & n (\%) & $\begin{array}{c}\text { OR } \\
(95 \% \text { CI })\end{array}$ & $\mathbf{p}$ & n (\%) & $\begin{array}{c}\text { OR } \\
(95 \% \mathrm{CI})\end{array}$ & $\mathbf{p}$ & n (\%) & $\begin{array}{c}\text { OR } \\
(95 \% \text { CI })\end{array}$ & $\mathbf{p}$ \\
\hline $\begin{array}{l}\text { Non-diabetic } \\
\text { (No-DM) }\end{array}$ & $\begin{array}{c}168 \\
(75.0)\end{array}$ & Ref. & - & $\begin{array}{c}23 \\
(10.3)\end{array}$ & Ref. & - & $\begin{array}{c}33 \\
(14.7)\end{array}$ & Ref. & - \\
\hline $\begin{array}{l}\text { No metformin } \\
\text { (DM-NoMet) }\end{array}$ & $\begin{array}{c}15 \\
(60.0)\end{array}$ & $\begin{array}{c}0.5(0.21 \\
1.17)\end{array}$ & 0.1 & $4(16.0)$ & $\begin{array}{c}1.66(0.53, \\
5.27)\end{array}$ & 0.4 & $\begin{array}{c}6 \\
(24.0)\end{array}$ & $\begin{array}{c}1.83(0.68 \\
4.91)\end{array}$ & 0.4 \\
\hline $\begin{array}{l}\text { Metformin } \\
\text { only } \\
\text { (DM-Met) }\end{array}$ & $\begin{array}{c}24 \\
(61.5)\end{array}$ & $\begin{array}{c}0.53(0.26, \\
1.08)\end{array}$ & 0.08 & $\begin{array}{c}12 \\
(30.8)\end{array}$ & $\begin{array}{c}3.88(1.74 \\
8.69)\end{array}$ & 0.001 & $3(7.7)$ & $\begin{array}{c}0.48(0.13 \\
1.66)\end{array}$ & 0.2 \\
\hline $\begin{array}{l}\text { Metformin \& } \\
\text { other } \\
\text { (DM-Met- } \\
\text { Other) }\end{array}$ & $\begin{array}{c}22 \\
(64.7)\end{array}$ & $\begin{array}{c}0.61(0.28, \\
1.31)\end{array}$ & 0.2 & $8(23.5)$ & $\begin{array}{c}2.68(1.09, \\
6.63)\end{array}$ & 0.032 & $\begin{array}{c}4 \\
(11.8)\end{array}$ & $\begin{array}{c}0.77(0.26 \\
2.33)\end{array}$ & 0.6 \\
\hline
\end{tabular}

CI: confidence interval; OR: odds ratio. 